\title{
How Family Business Leaders Can Encourage Both Devotion and Performance
}

\author{
Roland Kidwell (Florida Atlantic University) \\ Kathryn Kloepfer (Florida Atlantic University)
}

KEYWORDS: Management, Leadership, Family Business, Team Development.

Family businesses have unique strengths and unique problems because they blend two identities -- "family" and "business" -- whose priorities are often at odds. While the family identity nurtures strong commitment and selflessness among family members, the business identity prioritizes contributing to the firm's success and earning rewards rather than inheriting them. This can create problems associated with favoritism, distribution of unearned rewards and unethical behaviors when the two norms conflict. Human Resource Management (HRM) challenges are inevitable.

Some family firms' HRM practices prioritize the family values, emphasizing collaboration and reciprocal generosity because family member employees are viewed as dedicated and committed. Other firms use HRM approaches that prioritize monitoring because they view family member employees as opportunistic. This opportunism arises when family firm leaders are overly generous toward family employees, especially their adult children, offering them jobs and promotions regardless of their qualifications and refraining from disciplining their poor performance or dysfunctional behaviors. Ultimately, the family firm leader realizes that some fellow family members see the business solely as a source of their own enrichment, and that more controls are needed.

By monitoring employee behaviors, family firm leaders gather information about the work effectiveness and productivity of employees, which permits firm leaders to recognize and reinforce high-performing employees and to offer corrective feedback and reprimands to poor performers. But for family members accustomed to a collaborative HRM approach, a shift in focus from nurturing to monitoring can cause great dissatisfaction unless it's done right. Our recent research has shown that a balanced approach encourages employees to honor the needs of the business and go the extra mile.

\section{Monitoring vs. Collaboration}

Monitoring, which is believed to improve employee performance, can reduce family business employeerelated problems such as favoritism, entitlement and shirking. But it can also decrease the intrinsic motivation of monitored employees because they perceive that management doesn't trust them.

Conversely, a family firm leader who emphasizes the needs of the family rather than those of the business would likely take a collaborative approach to HRM. This type of collaborative focus encourages a collectivistic culture whereby harmony and long-term relationships are fostered. The advantages of a collaborative HRM approach are that open communication and strong bonds are believed to increase employee performance through an increased desire to help and be involved in the organization. But this can also lead to opportunities for family employees to shirk their duties and free ride on the work of others.

A recent article by Eddleston, Kellermanns and Kidwell in Human Resource Management argues for and tests a more balanced approach, emphasizing that both collaboration and monitoring can lead to higher levels of discretionary employee behaviors, known as extra-role behaviors. These extra-role behaviors are not part of the formal job requirements, but they make the company more efficient and effective if enough people embrace them.

Extra-role behaviors involve going beyond the call of duty and performing more than merely assigned tasks. Examples of such behaviors include assisting coworkers with a job-related problem; promoting a work environment that minimizes distractions created by interpersonal conflict; protecting and conserving organizational resources; etc. Whereas collaborative
Copyright ( 2018 The Authors. Entrepreneur \& Innovation Exchange is published at EIX.org. This is an open access article under the terms of the Creative Commons Attribution-NoDerivs License, which permits use and distribution in any medium, provided the original work is properly cited and no modifications or adaptations are made. View EIX.org Authorship Terms at https://eix.org/terms
FamilyBusiness 
efforts by family firm leaders, represented by behaviors that promote harmony and foster the development of long-term relationships, are likely to increase extra-role behavior, monitoring is likely to lead to decreased extrarole behaviors because it causes employees to feel distrusted at work. However, monitoring still may be necessary due to the opportunistic behaviors of family members. Unlike non-family firms, the mixed identity of family firms may call for a more complex approach toward HRM whereby both control and collaboration need to be integrated.

These arguments were tested through surveys sent to both family firm CEOs and family employees. A total of 81 matched (same firm CEO-employee) responses were analyzed and provided statistically significant evidence of the balanced HR approach. The main conclusion was that the control and collaboration elements may have complementary effects, and by bringing the disparate elements - control/collaboration, business/family - together, it may allow family firms to benefit from both the discipline and service orientations of family involvement.

\section{Integrating the Two Approaches}

So how exactly does a family business balance HRM practices related to collaboration and monitoring? Specifically, the study examined three factors -constructive confrontation, family harmony and adaptability - and their impact on a family firm environment in which collaboration may flourish amidst high monitoring.

\section{Constructive Confrontation}

Constructive confrontation refers to communication patterns and decision-making standards that embrace open expression and promote family employees' willingness to offer new and diverse viewpoints. For example, if a family employee is continuously missing deadlines and offering repetitive excuses, constructive confrontation would involve addressing the issue at hand as well as providing potential solutions. In discussing possible alternatives, constructive confrontation encompasses validating the rationale of employees, recognizing the difficulties and stress they may be feeling, and developing alternative courses of action with the help of the family employee. Family employees who report high constructive confrontation likely feel their viewpoints are valued. While one might expect that constructive confrontation, coupled with strong monitoring by the family leader, would help family employees identify new avenues for collaboration that help the family firm to achieve its goals, this is not necessarily the case. Higher levels of constructive confrontation did not make the relationship between strong monitoring and extra role behaviors more positive. Only in family firms with low monitoring did constructive confrontation encourage extra role behavior. Because constructive confrontation allows organizational members to see problems as requiring collaboration rather than competition, the presence of strong monitoring may lead to politicking and a greater emphasis on winning. This minimizes extra role behavior and puts control and collaboration at odds when considering constructive confrontation. However, the results regarding family harmony, adaptability, strong monitoring and extra role behavior were quite different.

\section{Family Harmony}

The second factor relating to how a firm can promote extra role behaviors while using both collaborative and monitoring HRM practices is family harmony. Family harmony captures the degree to which family members working in the firm get along with each other and possess a sense of compatibility, which can legitimize the family's role in the family firm. To maintain family harmony at work, it is important to assign roles, promote open and honest communication, and apply fair and just procedures. The presence of both high family harmony and monitoring should help the family understand their importance to the business, instead of viewing the firm as existing for the family to consume its resources. The absence of family harmony paired with higher levels of monitoring may prevent family employees from working together to reach firm goals and may spur distrust that undermines the family firm.

\section{Adaptability}

Adaptability also relates to extra-role behaviors of family employees in a family firm, using a balanced approach to HRM practices. Adaptability reflects the firm's willingness to challenge outdated traditions and demonstrate strategic flexibility and, when paired with monitoring, can help employees believe in their accountability for the future health of the family firm. Family employees' adaptability may be supported by, for example, offering a degree of autonomy in their roles, and may alter the negative effect of monitoring on extra-role behaviors by offering support and guidance to family employees as they search for new opportunities in their environment and recognize the need for 
changes.

\section{Yielding positive outcomes}

Family firm management should recognize that monitoring may diminish conscientious behavior and thus should be used wisely in family firms. However, as growing family firms attempt to implement high performance HRM systems as a strategic approach to enhance a firm's bottom line, these system implementations typically include monitoring, which may lead to employee perceptions of abusive supervision and distrust. Accordingly, a proper balance of control and collaboration can be crucial in ensuring that the workings of a high-performance HRM system yield positive outcomes and are not perceived as hostile or abusive by family member employees. This balance can be increasingly achieved through family harmony and adaptability, which help foster an environment where collaboration-like behaviors can flourish amidst high monitoring. Family firms that achieve this balance can expect higher employee engagement, an increase in recognition of innovative opportunities, and consequently a more productive and higher performing family business.

Additional search terms: Conflict in family business, family business members who don't get along, competition in family businesses, human resources in family business, managing a family business

\section{Reference}

Eddleston, K.A., F.W. Kellermanns, \& R.E. Kidwell. 2017. Managing family members: How control and collaboration affect extra role behavior in family firms. Human Resource Management. Published online. DOI: $10.1002 / \mathrm{hrm} .21825$.

https://onlinelibrary.wiley.com/doi/10.1002/hrm.21825 